\title{
On Change of Architectural Culture of Xuetang Academy
}

\author{
Hai Cheng \\ School of Fine Art \\ Huanggang Normal College \\ Huanggang, Hubei, China 438000
}

\author{
Yi Gong \\ Huangshi City No.8 High School \\ Huangshi, Hubei, China 435000
}

\begin{abstract}
As the first study built in Huanggang, Xuetang Academy is also Su Shi's residence when he stays in Huangzhou. Xuetang has just thatched cottages for sheltering at first. Yet after it is used as a study, the architectural style is converted towards Chinese structure of timber-frame covered with gray bricks and tiles. Reconstruction work that enables the academy to appear in superior level uses Chinese traditional architectural style of post and lintel construction or saddle roof. Containing particular cultural connotation, Xuetang is deemed as a sacred eastern land filled with wisdom and the "monumental construction" for scholarly attainments of $\mathrm{Su}$ Shi and it represents the totem of scholars studying Su Theory for Su Shi's literary achievements.
\end{abstract}

Keywords-Xuetang; architectural culture; transition

\section{INTRODUCTION}

Huanggang middle school is renowned in China not only for its passing on of educational wits. It can be said that Huanggang academy contributed to educational cultural legends in this era. Xuetang is the study that is built earliest in Guanggang, and numerous scholars was living there, such as Chao Gu, Yang Shichang, Cui Xian, Hu Dongwei, Liang Chong, Chen Jichang, Mi Fei, Zhang Shunmin, etc. Xuetang academy is also Su Shi's residence when he was living in Huangzhou, and in turn his literary achievements help promoted the reputation of the academy. Besides, the places that he frequently visited, such as Xuetang, Dinghui Yard and Lingao Pavilion, are subjects for researching nowadays. Researchers hold different views toward the accurate positions where $\mathrm{Su}$ stayed when he was in Songcheng, a place in Huangzhou. Their opinions are listed in "Table I" below.

TABLE I. SCHOlars' DifFERENT VIEWS ON THE ACTIVITIES Positions OF Sushi

\begin{tabular}{|l|l|l|l|l|}
\hline \multicolumn{1}{|c|}{ Scholar } & $\begin{array}{l}\text { Main Districts in } \\
\text { Songcheng }\end{array}$ & Xuetang Academy & $\begin{array}{l}\text { Lingao } \\
\text { Pavilion }\end{array}$ & Dinghui Yard \\
\hline Rao Xuegang & $\begin{array}{l}\text { Main part and } \\
\text { surroundings of } \\
\text { Mingcheng }\end{array}$ & $\begin{array}{l}\text { outside Mingcheng, from today's } \\
\text { Tiyu Road to Jiajia Street. }\end{array}$ & \\
\hline He Xueshan & $\begin{array}{l}\text { Area around } \\
\text { Qingzhuan Lake }\end{array}$ & $\begin{array}{l}\text { South of Dormitory of Huanggang } \\
\text { Daily Newspaper Printing plant }\end{array}$ & $\begin{array}{l}\text { Qingzhuan } \\
\text { Lake Haoerzui } \\
\text { area }\end{array}$ & $\begin{array}{l}\text { Qingzhuan Dinghua Yard } \\
\text { Lake and }\end{array}$ \\
\hline Zhang Longfei & $\begin{array}{l}\text { 1km around } \\
\text { Southern } \\
\text { Mingcheng }\end{array}$ & $\begin{array}{l}\text { Shisanpo, near the Municipal } \\
\text { Bureau of Commerce }\end{array}$ & $\begin{array}{l}\text { Former site of } \\
\text { Huanggang } \\
\text { Middle School }\end{array}$ & Supply Plant \\
\hline $\begin{array}{l}\text { Wang } \\
\text { Linxiang }\end{array}$ & $\begin{array}{l}\text { Maingcheng part of } \\
\text { Metween Qingyun Road and } \\
\text { Kaopeng Road }\end{array}$ & & \\
\hline
\end{tabular}

City wall of Songcheng in Huangzhou, located in present neighborhood around Yanhe Road, Bayi Road, Qingzhuan Lake Road and West Lake Road, is in square shape according to later study. It covers almost one square kilometers. The specific location of Xuetang Academy can be found by searching through the table above scholar.

Researches upon architectural cultural alternations reveals respect toward technology as well as culture.

Project source: funding project of general project of Hubei social science funds (No.2014204); funding project of Edong education and culture research center, key research base of humanities \& social sciences of Hubei regular institutions of higher learning (No .2014003403); research project of experiment teaching of 2014 experiment teaching demonstration center of Huanggang Normal College2014 (No. Zj201413).

\section{RESIDENCE}

Su shi was diminished and sent to Huangzhou in 1079. He had his own official position but entitled with no business. He stayed in the former site of Dinghui temple for a while. He mentioned in his letter that he was living with other monks while wearing linen clothes and having vegetarian foods for one meal a day. Life stayed simple. ${ }^{1}$ It has not been long that his household, almost 20 family members, came to Huangzhou. They stuck with financial problems and even had trouble feeding themselves. In his Replying Letter to Qin Taixu he depicted "I lead a poverty life. Every day I just use a little money to live by and I have to save the rest money for worse 
days, then I could hang the money on the beam by painting fork $^{2}$ ". Su Shi once applied to the government for reclaiming waste land in Huangzhou and wrote in Dongpo Eight Poems that: "since two years ago I came to Huangzhou, I have been in poverty and tiredness. An old friend Ma Zhengqing pitied me and he found some arable land available for me, then I had some land to till." The government agreed upon the idea of turning forest into farm land and building residence for living. $\mathrm{Su}$ named the camp he earned as Dongpo. Besides rice and wheat, he planted mulberry, jujube and tangerine trees, and he also cultivated more than ten acres of farming lands to grow vegetables. That place he stayed was an aesthetic picture of rural landscape.

Su Shi built five chambers on the eastern hill in 1081 . There was a heavy rain upon the accomplishment of the house. He wrote in Xuetang Memoirs that "Su found an abandoned park along the wing of Dongpo(east slope), then he renovated and decorated the park, taking it as a study and named it "Snow Study". The study was around by heavy snow. Since the snow was piled around the walls, there was no more spare space. Anytime you see was nothing but snow before your eyes in the repaired study. ${ }^{3,}$

These words reflect that Xuetang was a shabby shelter with nothing spectacular from inside out that he stayed when he was in Huangzhou. As a matter of fact, the development of ancient architecture in Song Dynasty can retrospect to administrative rules of the authority. The rules stated specific regulations for authorize housing and ordinary family housing. Yet in Song Dynasty, Huangzhou was the city for exiled personnel with old and shabby city facilities and low productivity. All residents there made their livings by farming that is relying on weather and most of them live in thatched cottages. According to repaired model of Xuetang Academy in "Fig. 1", it is a cottage functioning as a shelter, without tile covered for roof, and it has only mud walls and crude windows, with a plank as door, surrounded by stacked firewood. The appearance of former Xuetang is in accordance with Su's financial situation then. He could not afford any decorating or upholstering expense for this house.

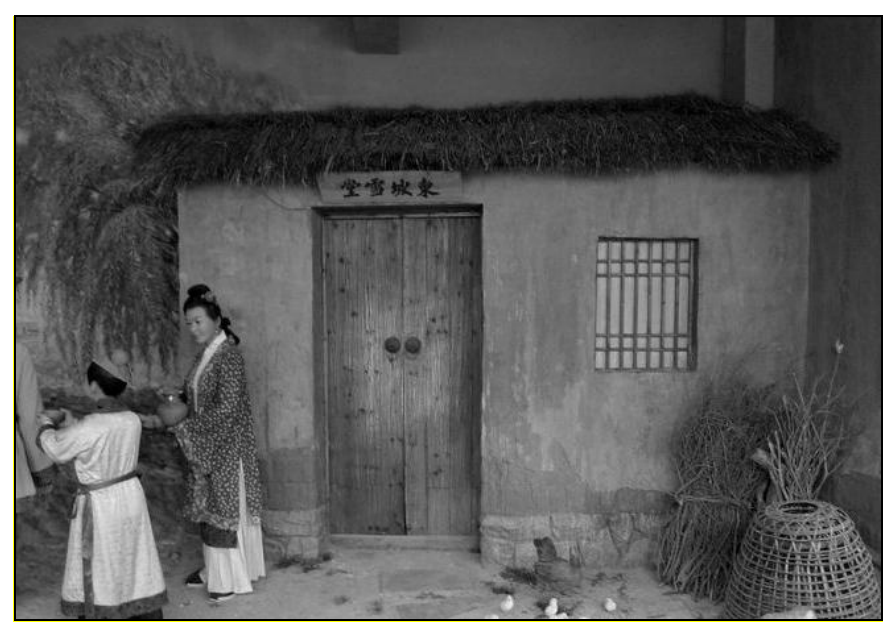

Fig. 1. Repaired Xuetang Academy
Present opinions hold that architectures with halls are referred as wealthy and influential family, which is distinct from what is described by $\mathrm{Su}$ in his letters when he wrote about Xuetang. It can be inferred that Xuetang is an imagined utopia exist only in literary works. It is the temporary shelter for $\mathrm{Su}$ that witnessed his transformation from an officer to a farmer. This is the place where he experienced the arduous farming work and hard living, then he gradually get accustomed to lifestyle of average Huangzhou residences. This period accounts for a key transforming point in his life. He changed his art life with generous mindset and achieved new peaks in his literary creations. He wrote substantial famous poems and articles such as The Rhyme on Chibi, Reflections at Chibi upon Ancient Heroes. He was later billed as a talent in five fields-poem, Chinese Ci poetry, article, calligraphy and painting.

The fact that Xuetang provides residence for eminent writers achieves its special historical value. It is simply a cultural symbol rather than its architectural scale or covering space.

\section{ACADEMY OF CLASSICAL LEARNING}

According to the record of Huanggang Chronicle, in 7th year of Yuanfeng (1084 AD), when Sushi left Huangzhou, he committed the Xuetang Academy to Pan Dalin and Chen Jichang for care, who were his friends. Pan Dalin, as a typical Jiangxi School poet, served and taught people in Xuetang Academy. The academy earned its fame for a moment, followers gradually grew up. Pan Dalin and Chen Jichang took advantage of an opportunity to establish a school and receive students, and it's the founding of Xuetang Academy.

Academy of Classical Learning, as the nongovernmental teaching organization of Han ethnic people, first appeared in Tang Dynasty. They ran many activities such as collecting books, adjusting books, mending books, writing books, carved block printing, reading books and teaching, etc. During Yuan and Ming Dynasty, there were 5 academies in Huanggang area of Hubei Province, including Dongpo Academy, Wenjin Academy, Confucius Academy, A'nan Academy. In Jiajing Era of Ming Dynasty, the academies in Huanggang grew as much as 305 , in which the Huangzhou, Jizhou and Macheng became most developed academies. By the record of Huanggang Chronicle, the Wenjin Academy in Huangzhou was the most famous school at that time, in Yuan Dynasty, Long Renfu settled and taught in this place. WenJin Academy then became an attractive area of Taizhou School. In Ming Dynasty, when the Li School, a Confucian school of idealist philosophy of the Song and Ming Dynasties, widely spread at that time, Zhu Xi, Wang Mingyang had several visits to many academies in Huanggang area. It made an all-round conclusion of Li School by Cheng Hao and Cheng Yi, and brought up a plenty of great ideologists and masters of Li School, as Geng Dingxiang, Geng Dingli, Geng Dinglee, Gu Wen and Gu Que. And three learning discussion centers, Tiantai Academy, Yangming Academy and Zhifo Academy, plus one art center of the imperial examination system, Wenjin Academy were well formed. 
For generations, academies had chosen their sites in hillrounded, quite place with beautiful scenes, so they were also ideal places for preparing exams, free from noise and distractions. Site selection on academies was determined by surrounding area, which needed the back hill should be 100200 meters higher than buildings, the mountain in both sides should be meandering downward, Black Dragon should be on left and White Tiger should be on right, the Black Dragon should a little bit higher than White Tiger, just like two arms bracing chest, becoming an independent trend. Most academies are built with common bricks and tiles, having an earthy style. They usually have Chinese traditional wooden structure, without luxurious brackets, rarely having colored drawing. The buildings are implicative changed and well arranged.

The building of Xuetang Academy can trace back in Sushi era, and there is no record in later generations, the building has been perished during the changing of dynasties, even its actual location become mystery. Lu You the poet wrote in Record on Visiting Sichuan and described "To the east of the gate of the capital city, the terrain was tough, to East Slope, the terrain suddenly became flat. A ridge in east was rather high. There were three houses; a ridge head called Laymen Pavilion, beneath the pavilion, there was a very magnificent hall, which was Xuetang Academy. There was another pavilion called Four Scoping Pavilion, which was just opposite to the academy. I enjoyed the beautiful scene on the top of the hill; it was the best place that having the best scene in whole province 4". From this record we can deduce that the Xuetang Academy was still very lofty on that moment, which was very different from the cottage by the record of Sushi. Zhu Yu of South Song Dynasty once said in Ping Zhou Talk about the academy, "When Su Shi demoted in Huangzhou, he established the Xuetang Academy, and called himself the Dongpo Layman, thus later generations call him Dongpo. The academy has now become a Buddhist temple." That means the academy had become a temple in South Song Dynasty, and its building type should have some change, but there is no record evidence. During Ming and Qing Dynasty, the Xuetang Academy was also recorded but seldom about its appearance. Since the ancient people had little record of the building, the original style of Xuetang Academy cannot be investigated and verified today.

While the Xuetang Academy was not a particular academy in Huangguang area, and gradually disappeared from people's sight like other academies, its statue and influence are still exist.

\section{MONUMENT}

After the founding of new China, many scholars on Sushi proposed to rebuild the Xuetang Academy, to memorialize Sushi and the earliest academy in Huanggang. Then the rebuilding was processed in 1986 "Fig. 2". The Xuetang Academy was rebuilt according to the standard of traditional academies. It locates in Longwang Mountain Park between Longwang Mountain and Yuji Mountain. It location is a concave ground in the middle of the two mountains. The whole project covers around 4000 squares meters "Fig. 3", "Fig. 4", around it there are green pines and verdant cypresses, as well as a small bridge over the flowing stream. In front of the Xuetang Academy, there is a pool, above the pool, there is a stony bridge. It also has a gateway with local traditional style, a U shape symmetrical structure with whitewashed wall and grey tiles. Commonplace reveals local cultural connotations. The Xuetang Academy was built according to the ancient building in China, built the new as the old, for emphasizing the ancient connotation. The main building can be divided by three parts, which are groundsill, body of building and housetop. A hip roof is adopted; all together there are 9 ridges lines on the roof, which is called Nine Ridge Roof, including one main ridge, 4 vertical ridges and 4 hip ridges. The two ends of main ridge break off in the middle of the eave, which are divided as vertical ridge and hip ridge. The top half of the roof is called saddle roof, and the lower part is called hip roof. The building reveals a magnificent sense with its combination of straight line and slant, forming a sense of straight and angular, as well as clear structure. The two sides of the roof form a triangle flower, dragon-head ridge ornament are carved on the main ridge. The whole roof looks color pragmatic, solemn atmosphere and appears the imposing manner is uncommon. Eaves surround the roof of the Xuetang Academy, with technology of anti-curved roof and warped corners, the roof and the corner look lighter and more lively. Ancient Chinese building should decorate itself and its ornaments. Vertical sides usually have most decoration, mainly on the doors and windows, as well as carved plates on partition boards. Carved plates are widely used in ancient Chinese building, it is a typical example for Chinese building technology, its consideration, work, methodology which reaches the peak of perfection, and its line looks simple and smooth. The vertical sides of the Xuetang Academy are decorated with blossom patterns "Fig. 5", "Fig. 6", the whole vertical side is partite and recombined a plate with single pattern, which seems unified and generous, simple and elegant. At the entrance of the academy, a plaque said two characters "Xuetang Academy". The four sides of groundsill are built by stony bricks, filled with soil inside and paved bricks outside. All these make the building looks firm and solid, upright and foursquare. In addition, both two sides have foot stamps with hanging stone.

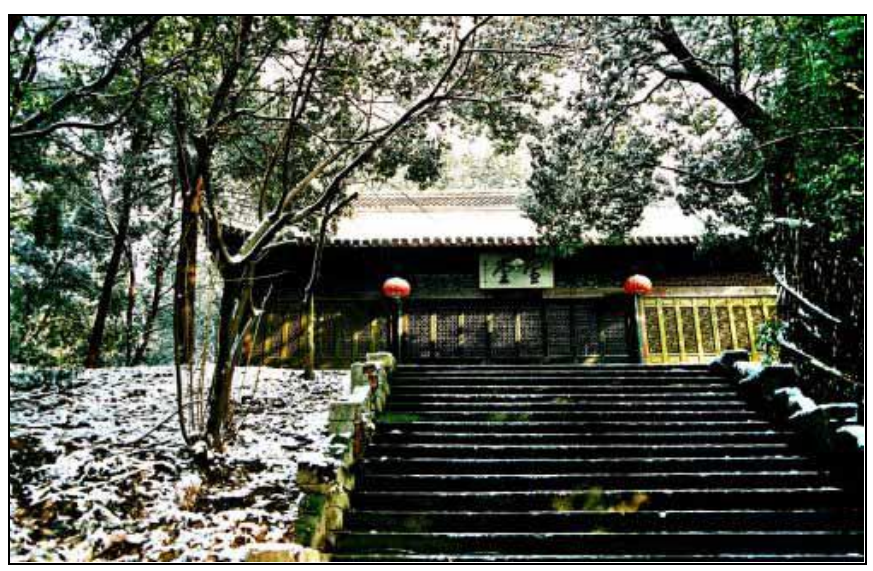

Fig. 2. Present Xuetang Academy 


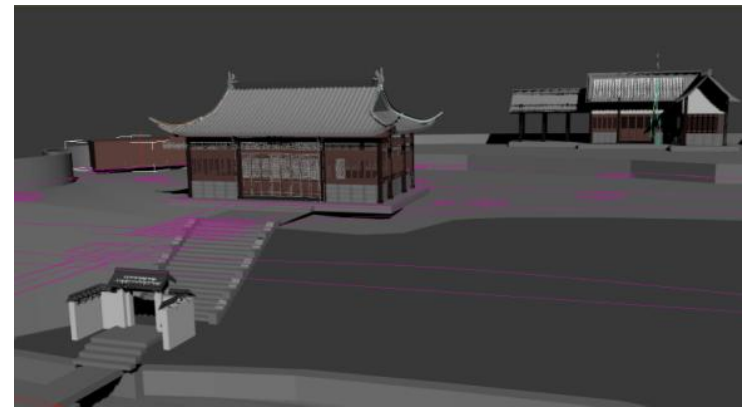

Fig. 3. Digital model Panorama of Xuetang Academy

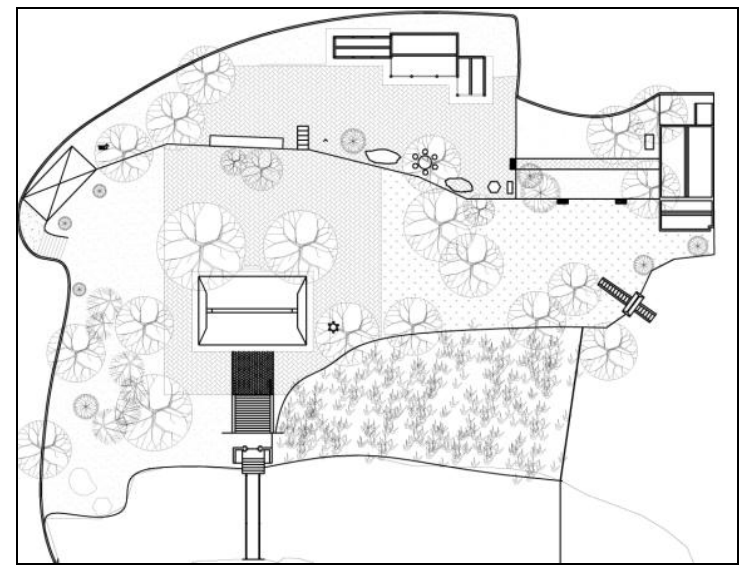

Fig. 4. General plan figure of Xuetang Academy

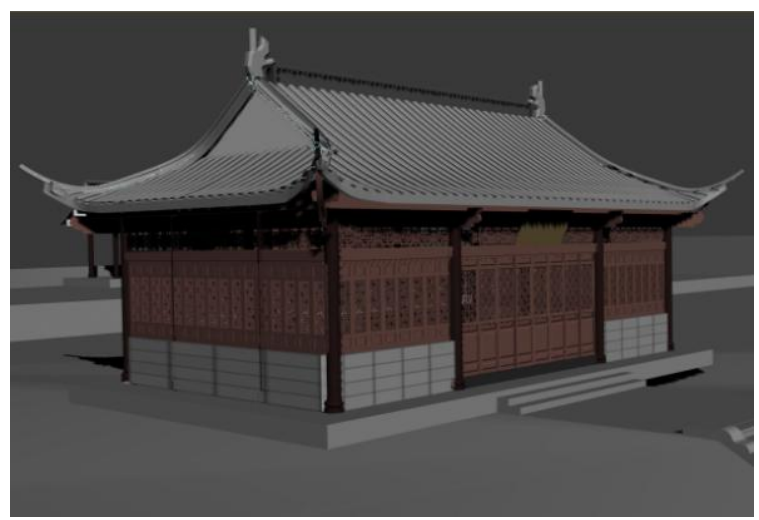

Fig. 5. Digital model perspective drawing of Xuetang Academy

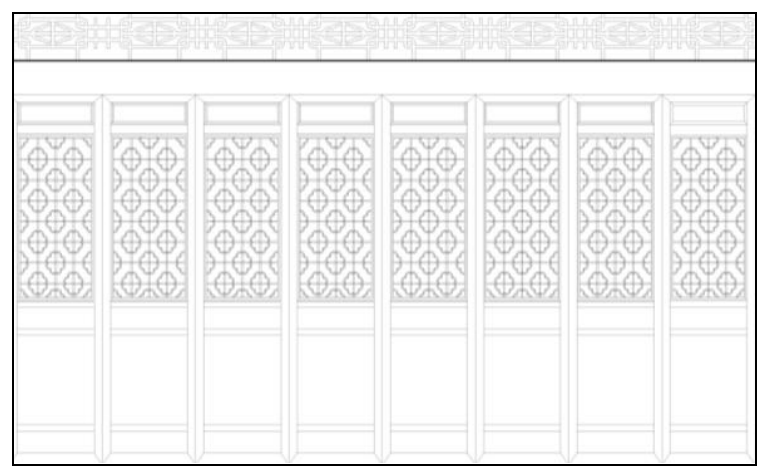

Fig. 6. Gate picture pattern of Xuetang Academy
The Xuetang Academy adopts traditional lift beam structure, three rooms with five structures, established pillars on their base, installed beams on pillars, overlapped two-story short column and beam, put short column on the top beam, forming the roof truss. Top ends of the pillars are linked through tie beams in order to connect the two groups of parallel structures. Purlins were installed to the beams and short columns in each layers to link structure and bear the roof covering. Rafters are installed among the purlins to form the main structure of the roof. The middle part of the Xuetang Academy is the main hall, east part is the bedroom, and west part is a reception room. It is in main hall where display the Picture of Dongpo in Farming, the Picture of Plums Blossom in Snow and the Picture of Xuetang Academy in Snow. In Reception Room, there is the Su's famous "Dongpo Eight Poems", which is written by the famous Japanese calligrapher Kato Hoshimine.

Upon completion, the academy has received both positive and negative comments. While there is no students read aloud in the Academy today, it has become a famous site for doing morning exercise and enjoying leisure time in Huangzhou. Different from the residence for $\mathrm{Si}$, or cultural institute for Chen Jichang, the Xuetang Academy has already transformed from a cottage to an oriental paradise in people's heart. The transition of time makes the academy to be a monumental building ${ }^{6}$, which represents the symbol which prostrates the scholars on $\mathrm{Su}$ in worship to the achievement in literature of $\mathrm{Su}$ Dongpo. Scholars of Su Theory always visit the Xuetang Academy when they arrive Huangzhou. People did not pay attention to the original style of the academy long before, but they treat the place as a spiritual sanctum.

\section{CONCLUSION}

The original core of buildings is to provide residences, the style of building will be changed when the certain cultural destiny in it altered. The style will influence people's audiovisual effect by its cultural connotation. When people try to rebuild the damaged structure, the form will be close to the related culture, and the culture will intangibly influence the size and scale of the buildings. Like many cultural buildings and cultural commercial streets today, that is developed by the relation between buildings and culture. It will create a good result if developed in a proper way.

\section{REFERENCES}

[1] Mo Lifeng, Manhua Dongpo [M], Nanjing: published by Phoenix Publishing House, 2008

[2] Cui Zhonglei, Collected Works of Eight Masters in Tang and Song Dynasties[M], Harbin: Harbin Publishing House, 2012

[3] Su Shi (Song), Collected Works of Su Shi [M], Changsha: Yuelu Publishing House, 2000

[4] Lu You (Song), Rushuji, Notes of Laoxuean [M], Shanghai: Shanghai Far East Publishing House, 1996

[5] Zhu Yu (Song), Pingzhou Ketan [M], Beijing: Zhonghua Press, 2007

[6] Wu Hong (U.S.), Li Qingquan, Zheng Yan (Translated), Monument in ancient Chinese art and architecture [M], Shanghai: Shanghai People's Press,2009. 